\title{
Comparative evaluation of Ferric Sulfate, Electrosurgical and Diode Laser on human primary molars pulpotomy: an “in-vivo" study
}

\author{
PYadav $^{1}$, KR Indushekar ${ }^{1}$, BG Saraf $^{1}$, N Sheoran ${ }^{1}$, D Sardana ${ }^{1}$ \\ 1: Sudha Rustagi College of Dental Sciences and Research, \\ Department of Pediatric Dentistry, Faridabad, India.
}

\begin{abstract}
Background and aims: Despite modern advances in the prevention of dental caries and increased understanding of the importance of maintaining the natural primary dentition, many teeth are still lost prematurely. This can lead to malocclusion with aesthetic, phonetic and functional problems that may be transient or permanent. Therefore, maintaining the integrity and health of the oral tissues is the primary objective of pulp treatment. Pulpotomy has remained an acceptable and mainstay treatment in preserving the vitality of primary tooth and prolonging its life till the permanent successor erupts. Various materials and techniques are available for pulpotomy on primary molars; all with some advantages and disadvantages. The present study was carried out on 45 primary molars to evaluate and compare the clinical and radiographic success of diode laser, electrosurgical and ferric sulfate pulpotomy over a period of 9 months.

Materials (Subjects) and Methods: The forty five primary molars were randomly and equally divided into three treatment groups which were as follows: Group A: 15 primary molars treated with $15.5 \%$ Ferric sulfate Group B: 15 primary molars treated with electrosurgical unit and Group C: 15 primary molars treated with diode laser. All teeth in three categories were followed up clinically and radiographically at 1, 3,6 and 9 months post treatment and the findings were recorded on the prepared proforma

Results: Clinically, $86.6 \%$ success rate was found in ferric sulfate group whereas $100 \%$ success rate was found in electrosurgical and diode laser groups. Radiographically, 80\% success rate was found in all the three groups at the end of 9 months with internal resorption being the most common cause of failure after pulpotomy.

Conclusions: Thus, electrosurgery and diode lasers appear to be acceptable alternative to pharmacotherapeutic pulpotomy agents.
\end{abstract}

Key words: Pulpotomy $\cdot$ Diode Laser $\cdot$ Electrosurgery $\cdot$ Ferric Sulfate

\section{Introduction}

The treatment of the dental pulp in deciduous teeth exposed by the caries process, by accident during cavity preparation, or even as a result of injury and fracture of the tooth has long presented a challenge in treatment. Despite modern advances in the prevention of dental caries and or increased understanding of the

\section{Addressee for Correspondence:}

Dr. Divesh Sardana MDS,

Department of Pediatric Dentistry, SRDC, Faridabad, India.

Phone no: +91-9711886932.

Email: doc_divesh@yahoo.co.in importance of maintaining the natural primary dentition, many teeth are still lost prematurely. This can lead to malocclusion with aesthetic, phonetic and functional problems that may be transient or permanent. Therefore, maintaining the integrity and health of the oral tissues is the primary objective of pulp treatment. Pulpotomy has become the dominating pulp therapy for the deciduous dentition, because of the complicated anatomy of the root canals in primary teeth, the proximity of the permanent tooth germ and the difficulties in finding a root-canal filling material compati-

Received Date: November 28th, 2013

Accepted Date: February 19th, 2014 
ble with physiological root resorption ${ }^{1)}$. Pulpotomy in primary teeth can be defined "as the amputation of the affected and infected coronal portion of the dental pulp, preserving the vitality and function of all or part of the remaining radicular pulp" ${ }^{2}$ ). It is based on the rationale that the radicular pulp tissue may be healthy or capable of healing after surgical amputation of the affected or infected coronal pulp ${ }^{3}$ ). It is a conservative therapy performed to remove the inflamed coronal pulp tissues followed by application of an effective and compatible bactericidal medicament which encourages the tissue in the root canals to remain vital.

Formocresol has been regarded as the gold standard and remains the most commonly used material for pulpotomies due to its good fixative and bacteriostatic properties ${ }^{4}$ ). However, the use of formocresol for management of exposed vital pulp has been debated vigorously over the last two decades due to its concern over potential toxicity, mutagenicity and carcinogenicity in humans. Due to the safety concerns over formocresol, research for better and safer alternatives for pulpotomy has been underway over the years. Hence the present study was carried out to compare and evaluate the clinical and radiographic success of Ferric Sulfate, Electrosurgery and Diode Laser Pulpotomy on human primary molars over a period of 9 months.

\section{Materials and methods}

The present longitudinal study was carried out on 45 primary molars in 37 children (age group 4-7 years) at Sudha Rustagi Dental College, Faridabad over a period of 9 months. Ethical approval was obtained from institutional ethics board and written consent was taken from all the patients before including them in the study.

\section{Inclusion criteria-}

\section{Clinical criteria}

a) No spontaneous pain

b) No swelling

c) No tenderness on percussion

d) No pathological mobility

e) No sinus tract opening

f) No initially unsuccessful hemorrhage control.

\section{Radiographic criteria}

a) Teeth without inter-radicular radiolucency

b) No loss of lamina dura and widened periodontal ligament space c) No physiologic root resorption of more than onethird.

\section{Exclusion criteria-}

1. Primary molars with swelling or fistula.

2. The teeth which were non restorable.

3. Teeth with marked tenderness to percussion.

4. Teeth with excessive mobility.

5. Teeth with radiolucency in the furcal or periapical area.

6. Teeth with spontaneous pain, especially at night.

7. Teeth with necrotic pulp.

8. Teeth near to exfoliation.

9. Parents / Patients not willing to be the part of study.

10. Any kind of medical history contraindicating the pulp treatment.

The forty five primary molars were randomly and equally divided into three groups which were as follows:

Group A: 15 primary molars treated with $15.5 \%$ Ferric sulfate

Group B: 15 primary molars treated with electrosurgical unit and

Group C: 15 primary molars treated with diode laser.

The tooth was first profoundly anesthetized followed by rubber dam application. A standard sterilization protocol was followed for all the procedures. Initially with a no. 4 round bur (slow speed) all the carious dentin from the floor and the lateral walls of the cavity was removed before entering the pulp chamber. Later a straight fissure bur no 2 with a high speed air rotor and water coolant was used to locate the pulp horns. Cuts were made between these horns so as to remove the entire roof of the pulp chamber and to gain a direct access to the pulp chamber. The coronal pulp was removed with sterile sharp spoon excavator taking care no coronal pulp was left in the chamber. Later the pulp chamber was irrigated with saline. Post amputation bleeding was controlled by sterile moist cotton pellet soaked in saline and placed over the amputated root stumps for five minutes under pressure. Then the amputated stumps were checked for bleeding. If haemorrhage still persisted the tooth was excluded from the study and if haemorrhage was successfully controlled, it was continued for the application of the pulpotomy medicaments depending on the following groups.

Group A - A cotton pellet was first saturated with $15.5 \%$ ferric sulfate and later compressed between gauze to remove excess so it was just moistened with 
the solution. It was then placed for 15 seconds on amputated pulp stumps. After this the pulp stumps were observed for brownish to black discoloration of the fixed radicular pulp tissue. Excess Ferric sulfate was flushed from the pulp chamber with copious amount of saline and clot remnants were removed from the chamber followed by placement of a thick mix of zinc oxide eugenol into the pulp chamber.

Group B - The ART-E1 electrosurgery unit (Bonart Co. Ltd., Taipei Hsien, Taiwan) was set at COAG 1 mode to perform both electrofulguration and electrocoagulation. The handpiece with appropriate electrode tips, kept 1-2mm away from the pulpal tissue, was used to deliver the electric current. The duration of application was not more than 2-3 seconds followed by a cool down period of 5 seconds. If necessary, this procedure was repeated up to a maximum of three times. After each current application, a new large moist sterile cotton pellet was placed with pressure on the pulpal tissue near to orifice to absorb any blood or tissue fluids before the next current application (e.g. pellet-electrode-pellet-electrode). When properly completed, the pulpal stumps appeared dry and completely blackened (Figure 1). This was followed by placement of a thick mix of zinc oxide eugenol into the pulp chamber.

Group C - The remaining coronal pulp tissue was exposed to laser energy through an optical fibre using the diode laser (Picasso, AMD Lasers, Indianapolis, USA Wavelength: $810 \mathrm{~nm}$, output power: $7 \mathrm{w}$ ) set at 3 W of power in Continuous Wave. The laser energy was delivered through a $400 \mu \mathrm{m}$ diameter optical fibre in a non contact mode with pulp tissue for not more than

2-3 sec $(\mathrm{PD}=2388.53$, Fluence $=7165.60)$. Application of laser was administered until the pulp was ablated and complete haemostasis was achieved (Figure 2). All patients and clinical staff wore appropriate eye protection during application of the laser. Applications were administered as per the requirement of each tooth followed by placement of a thick mix of zinc oxide eugenol into the pulp chamber.

Then in each group, the tooth was restored with restorative glass ionomer cement. Immediately after the pulpotomy procedure, a standardized postoperative Intra-oral Periapical Radiograph or a radiovisiograph was taken. For a few patients stainless steel crown was placed immediately and for others a subsequent appointment on the next day was given depending on the cooperation of the patient.

All teeth in three categories were followed up clinically and radiographically at 1, 3, 6 and 9 months post treatment and the findings were recorded on the prepared Performa.

The success and failure results was then evaluated on the basis of the following criteria -

\section{Clinical success evalua- tion criteria}

1. Absence of pain and tenderness.

2. Absence of abscess.

\section{Absence of sinus or} fistula.

4. Absence of mobility.

\section{Radiographic success} evaluation criteria

1. Absence of widened periodontal space.

2. Absence of inter-radicular or periapical radiolucency

\section{Absence of internal} resorption

4. Absence of abnormal canal calcification

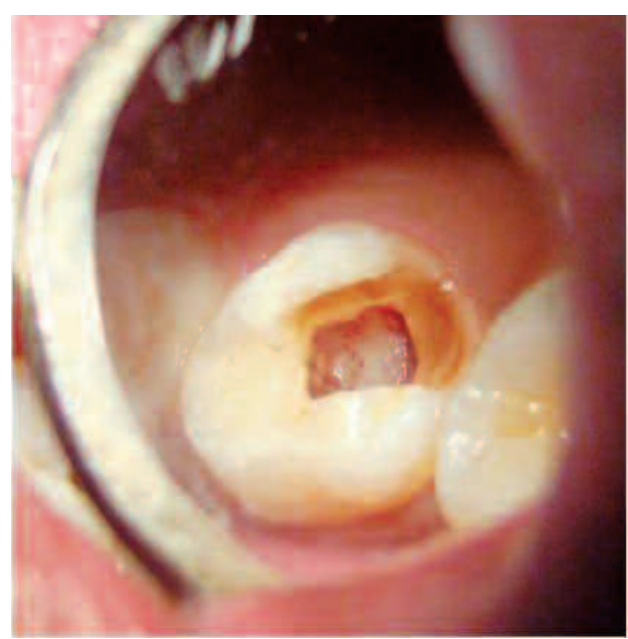

Figure 1: Appearance of Pulp chamber following Electrosurgical pulpotomy

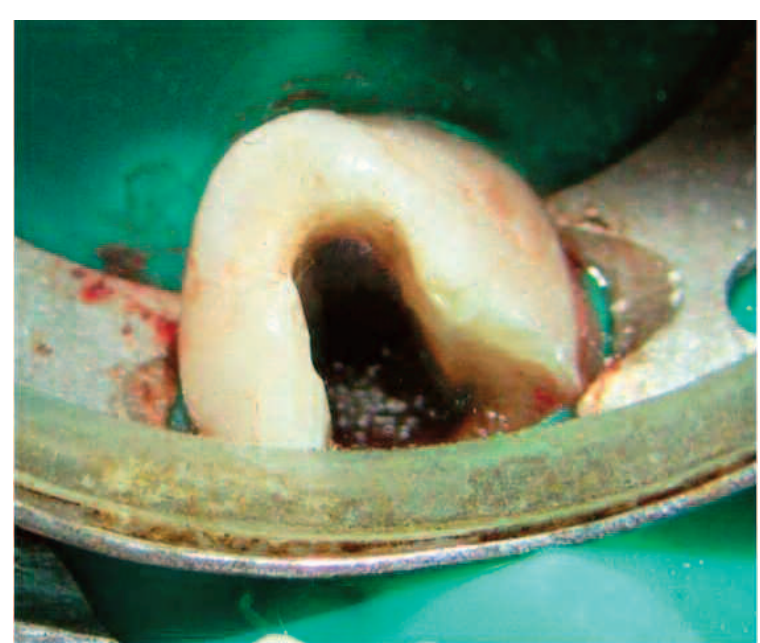

Figure 2: Appearance of Pulp chamber following Diode Laser Pulpotomy 
The statistical analysis was done using SPSS (Statistical Package for Social Sciences) Version 15.0 statistical Analysis Software. Kruskal-Wallis and Anova were used to determine the significance levels among the three groups.

\section{Results}

Clinical Success (Table 1): The overall clinical success was found to be $86.6 \%(13 / 15)$ in the Ferric Sulfate group whereas $100 \%$ success rate was recorded in both electrosurgical and diode laser groups. One failure in Ferric Sulfate group occurred at 3 month follow-up whereas the other failure occurred at 6 month followup; both due to pain and tenderness. The difference between the three groups was not found to be statistically significant $(\mathrm{p}=0.99)$

Radiographic success (Table 2): At the end of 9 months, all the groups showed 3 failures each giving an overall success rate of $80 \%$ each respectively. Ferric Sulfate group showed 2 failures due to internal resorption and 1 due to inter radicular radiolucency (Figure

Table 1: Summary of the clinical evaluation of follow up at different time intervals till 9 months

\begin{tabular}{|c|c|c|c|c|c|c|c|c|c|c|c|c|c|c|c|c|}
\hline \multirow[b]{2}{*}{ Clinical parameter } & \multirow[b]{2}{*}{ Total } & \multicolumn{3}{|c|}{ 1month } & \multicolumn{3}{|c|}{3 months } & \multicolumn{3}{|c|}{ 6months } & \multicolumn{3}{|c|}{ 9months } & \multicolumn{3}{|c|}{ Total Failures } \\
\hline & & FS & ES & $\mathrm{DL}$ & FS & ES & $\mathrm{DL}$ & FS & ES & $\mathrm{DL}$ & FS & ES & $\mathrm{DL}$ & FS & ES & $\mathrm{DL}$ \\
\hline Pain and tenderness & 45 & 0 & 0 & 0 & 1 & 0 & 0 & 1 & 0 & 0 & 0 & 0 & 0 & 2 & 0 & 0 \\
\hline Abscess & 45 & 0 & 0 & 0 & 0 & 0 & 0 & 0 & 0 & 0 & 0 & 0 & 0 & 0 & 0 & 0 \\
\hline Sinus/ fistula & 45 & 0 & 0 & 0 & 0 & 0 & 0 & 0 & 0 & 0 & 0 & 0 & 0 & 0 & 0 & 0 \\
\hline Mobility & 45 & 0 & 0 & 0 & 0 & 0 & 0 & 0 & 0 & 0 & 0 & 0 & 0 & 0 & 0 & 0 \\
\hline Total failures & & & & & & & & & & & & & & 2 & 0 & 0 \\
\hline
\end{tabular}

Table 2: Summary of the radiographic evaluation follow-up at different time intervals till 9 months

\begin{tabular}{|c|c|c|c|c|c|c|c|c|c|c|c|c|c|c|c|c|}
\hline \multirow[b]{2}{*}{ Radiographic parameter } & \multirow[b]{2}{*}{ Total } & \multicolumn{3}{|c|}{1 month } & \multicolumn{3}{|c|}{3 months } & \multicolumn{3}{|c|}{6 months } & \multicolumn{3}{|c|}{9 months } & \multicolumn{3}{|c|}{ Total Failures } \\
\hline & & FS & ES & DL & FS & ES & $\mathrm{DL}$ & FS & ES & DL & FS & $\mathrm{ES}$ & DL & FS & ES & DL \\
\hline Widened periodontal space & 45 & 0 & 0 & 0 & 0 & 0 & 0 & 0 & 0 & 0 & 0 & 0 & 0 & 0 & 0 & 0 \\
\hline Interradicular or periapical radioluscencies & 45 & 0 & 0 & 0 & 1 & 0 & 0 & 0 & 0 & 0 & 0 & 0 & 0 & 1 & 0 & 0 \\
\hline Internal resorption & 45 & 0 & 1 & 0 & 0 & 2 & 1 & 1 & 3 & 3 & 2 & 3 & 3 & 2 & 3 & 3 \\
\hline Abnormal canal calcification & 45 & 0 & 0 & 0 & 0 & 0 & 0 & 0 & 0 & 0 & 0 & 0 & 0 & 0 & 0 & 0 \\
\hline Total failures & & & & & & & & & & & & & & 3 & 3 & 3 \\
\hline
\end{tabular}

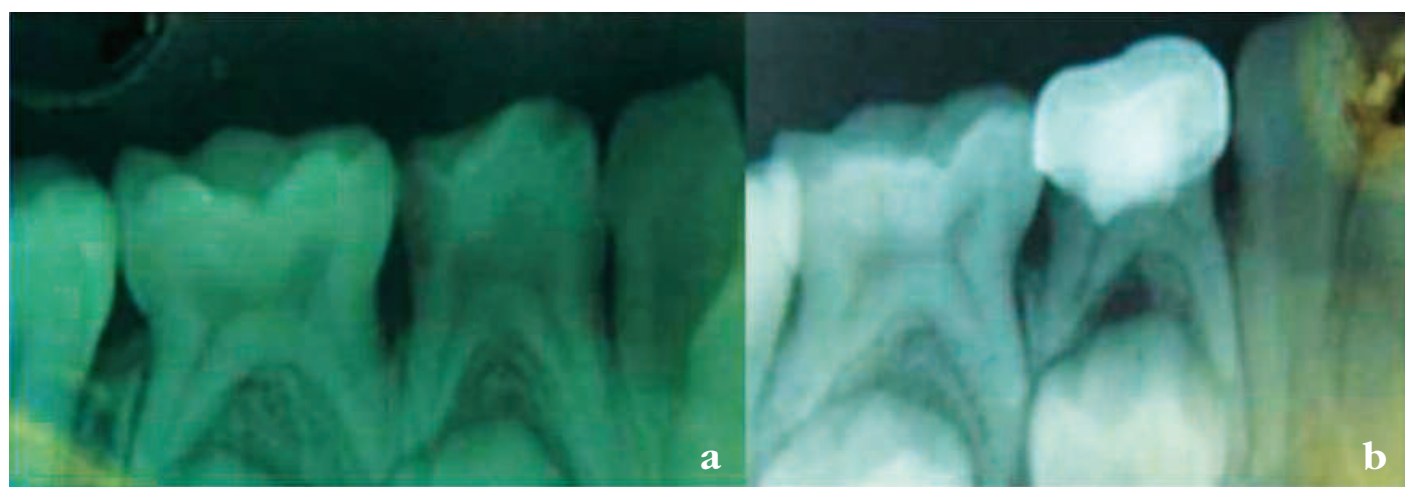

Figure 3: a. Pre-operative (Ferric Sulfate group) b. 3 months post-operative (Note the Inter-radicular radiolucency) 
3) whereas internal resorption was the cause of all three failures in other two groups (electrosurgery and diode laser) (Figure 4, Figure 5).

\section{Discussion}

Overall Success: Success or failure of pulpotomy is dependent on various factors such as: an accurate diagnosis at the time of, operator's skill of diagnosis, the extent of pulpal inflammation, pulpotomy agent used, technique of using that agent, healing reaction of individual pulp, lining material used, adequate coronal seal, period of observation and the criteria used to determine the success or failure of the procedure. In the present study, the overall clinical and radiographic success of Ferric sulfate group is $86.6 \%$ and $80 \%$ respectively, for the Electrosurgical group is $100 \%$ and $80 \%$ respectively and for the Diode Laser group is $100 \%$ and $80 \%$ respectively with no significant difference between any group at the end of 9 months which is in agreement with most of the studies in literature. The overall clinical success of Ferric sulfate pulpotomy from the studies ranges from $78 \%-100 \%$ while the overall radiographic success varies from $43 \%$ - 97\% 5-
13). Whereas for Electrosurgical pulpotomy clinical success ranged from $87.5 \%$ - 100\% while radiographic success was $84 \%-96.8 \%$. ${ }^{14-17)}$. For the Laser pulpotomy the clinical success ranges from $85.71 \%-100 \%$ while the radiographic success varies from $67 \%-94.1 \%$. 13, 18-22)

Internal resorption: In the present study internal resorption was noted in all pulpotomy medicament groups. The number of teeth involved with internal resorption gradually increased from the 1 month to 9 months of follow-up period. In the Ferric sulfate group, there were in total 2 teeth (13.33\%) which showed internal resorption at the end of 9 months follow up while in the Electrosurgical group and Laser groups, there were in total 3 teeth (15\%), each which showed internal resorption at the end of 9 months follow up. This finding is comparable to following studies. Fuks et al (1997) ${ }^{6}$ ) reported $7.3 \%$ cases of internal resorption after 34 months with ferric sulfate. Similarly Casas et al (2003) ${ }^{7)}$, Ibricevic \&Al-Jama (2003) 9), Smith et al (2000) ${ }^{8)}$ and Vargas \& Packham (2006) ${ }^{23)}$ reported $55 \%, 3 \%, 17 \%$ and $24 \%$ of internal resorption after a follow up period of 2 years respectively. Also Huth et al (2005) 13) and Papagiannoulis (2002) 11)

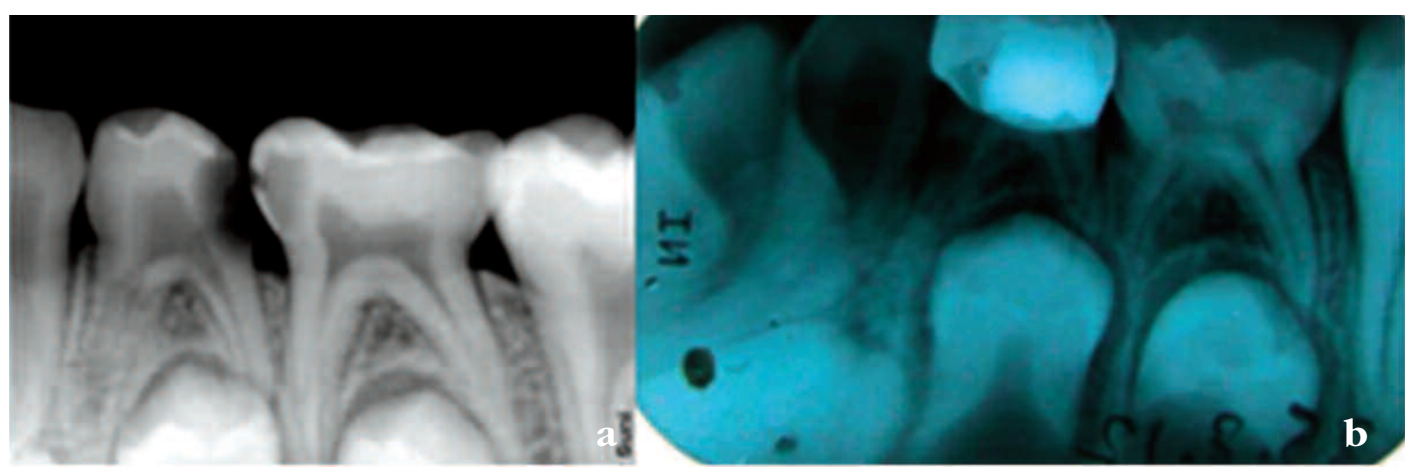

Figure 4: a. Pre-operative b. 3-months post-operative (Internal resorption in Diode Laser group)
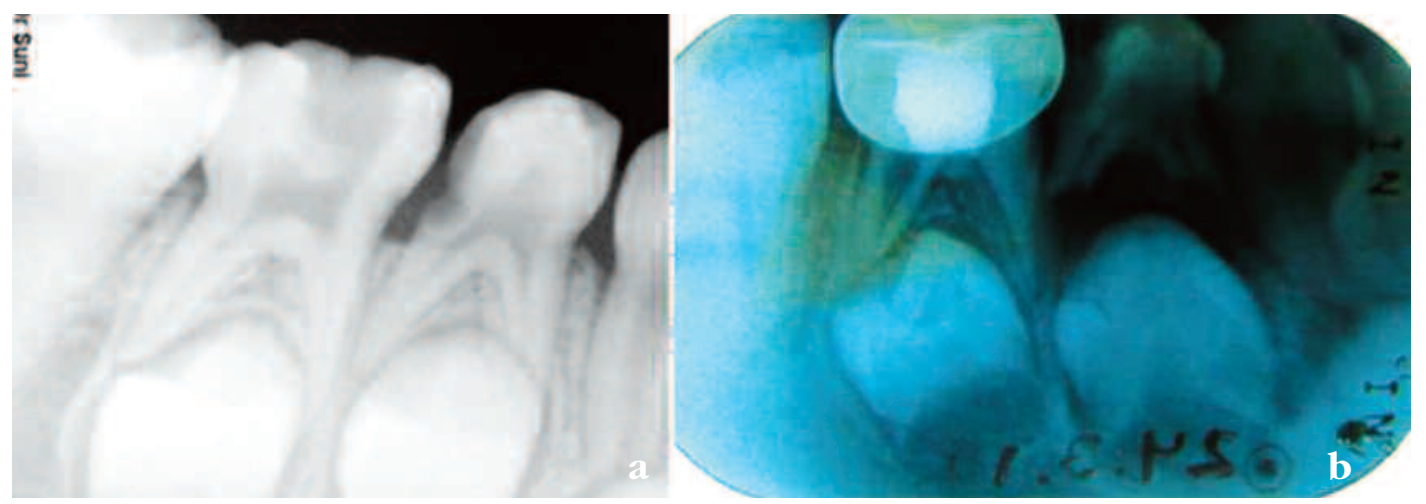

Figure 5: a. Pre-operative b. 9 months post-operative (Internal resorption see in electrosurgery pulpotomy group) 
showed a failure of $4 \%$ and $21.9 \%$ of internal resorption after a 24 months follow up period. Bahrololoomi et al (2008) 16) observed internal resorption in two teeth in the sixth and ninth month recalls while comparing electrosurgical pulpotomy and formocresol pulpotomy. Internal resorption without clinical signs or symptoms of morbidity was also noted by Mack and Dean (2002) ${ }^{15)}$ in the electrosurgical group.

Inter-radicular pathology: In the present study, no inter radicular radiolucency was seen in Electrosurgical or Laser group while only one case (6.6\%) from the ferric sulfate group had inter radicular radiolusceny at 3 months follow up. Pathological inter-radicular radiolucency was similarly exhibited in Ferric sulfate pulpotomies by different authors. Fuks and Eidelman (1997) 6) reported 3.6\% cases with inter radicular radiolucency after 36 months, while Casas et al (2003) ${ }^{7)}$, Smith et al (2000) ${ }^{8}$ ) and Huth et al (2005) 13) reported failure in $27 \%, 13.2 \%$ and $6 \%$ cases following 3 years, 57 months and 24 months follow up period respectively. Pathological inter radicular radiolucency may be attributed to the rapid spread of inflammation in primary teeth and also to the seepage of the medicament, bacteria and their toxins into the apical region through the root canals from accessory canals or furcation area which are usually thin, porous and permeable in deciduous molars.

The relatively benign nature of electrosurgical pulpotomy treatment and laser assisted pulpotomy as compared to pharmacotherapeutic pulpotomy procedures was found to be encouraging in the present study. Lasers in Pediatric dentistry have also been used for various other purposes like: diagnosis of carious lesions ${ }^{4}$, analgesic effect of dentin ${ }^{25}$ ), preparation of dentin before composite bonding ${ }^{26)}$, treatment of ankyloglossia and frenal attachments 27 ). Lasers have been used in pediatric dentistry because of its advantages like reduced chair side time, elimination of high speed drill and elimination of pain due to injectionsall of which are barriers to effective dental treatment for children. The main advantages of laser-assisted pulpotomies were: less chair side time and painless procedure thus increasing pediatric patient's co-operation. Ruemping et al (1983) ${ }^{28)}$ identified electrosurgical pulpotomy advantages that can be applied to the controlled energy category at large and include- (1) Quick and efficient (2) Self-limiting (3) Good hemostasis (4) Good visibility of the field (5) No systemic effects and (6) sterilization at the site of application. However; electrosurgical pulpotomy appears to need a more sensitive diagnosis. Another consideration with electrosurgical pulpotomy is the lateral heat production that is why a 10-15 seconds interval was given for cooling as the heat build-up might lead to side effects. Another disadvantage of this technique can be the smell after the tissue burns during the procedure which can possibly lead to alteration in the child's behavior. Ferric sulfate as a pulpotomy medicament has advantages of being easily available, easy handling and manipulation, no heat produced and no electricity required, cost effective than Electrosurgery unit and Diode Laser and no special skills required to use unlike Electrosurgery unit and Diode Laser equipment.

\section{Conclusions}

The present in-vivo longitudinal study was carried out on 45 deciduous molars to evaluate the clinical and radiographic success of Ferric Sulfate, electrosurgical and Diode Laser pulpotomies over a period of 9 months. Clinically, $86.6 \%$ success rate was found in ferric sulfate group whereas 100\% success rate was found in electrosurgical and diode laser groups. Radiographically, 80\% success rate was found in all the three groups at the end of 9 months with internal resorption being the most common cause of failure after pulpotomy. Thus, electrosurgery and diode lasers appear to be acceptable alternative to pharmaco-therapeutic pulpotomy agents.

Success of electrofulguration pulpotomies covered by zinc oxide and eugenol or calcium hydroxide: a clinical study. Pediatr Dent, 18:385-90.

5: Fei AL, Udin RD, Johnson R (1991). A clinical study of ferric sulfate as a pulpotomy agent in primary teeth. Pediatr Dent, 13:327-32.

6: Fuks AB, Eidelman E, Cleaton-Jones P, Michaeli Y (1997). Pulp response to ferric sulfate, diluted 
formocresol, and IRM in pulpotomized primary baboon teeth. ASDC J Dent Child, 64:254-59.

7: Casas MJ, Layug MA, Kenny DJ, Johnston DH, Judd PL (2003). Two-year outcomes of primary molar ferric sulfate pulpotomy and root canal therapy. Pediatr Dent, 25:97-102.

8: Smith NL, Seale NS, Nunn ME (2000). Ferric sulfate pulpotomy in primary molars: a retrospective study. Pediatr Dent, 22:192-9.

9: Ibricevic H, Al-Jame Q (2003). Ferric sulfate and formocresol in pulpotomy of primary molars: long term follow-up study. Eur J Paediatr Dent, 4:28-32.

10: Casas JM, Kenny DJ, Johnston DH, Judd PL (2004). Long-term outcomes of primary molar ferric sulfate pulpotomy and root canal therapy. Pediatr Dent, 26:44-48.

11: Papagiannoulis L (2002). Clinical studies on ferric sulfate as a pulpotomy medicament in primary teeth. Eur J Paediatr Dent, 3:126-32.

12: Neamatollahi H, Tajik A (2006). Comparison of clinical and radiographic success rates of pulpotomy in primary molars using Formocresol, Ferric Sulfate and Mineral Trioxide Aggregate (MTA). J Dent, 3:7-14.

13: Huth KC, Paschos E, Hajek-Al-Khatar N, Hollweck R, Crispin A, Hickel R, Folwaczny M (2005). Effectiveness of 4 Pulpotomy TechniquesRandomized Controlled Trial. J Dent Res, 84:114448.

14: Mack RB, Dean JA (1993). Electrosurgical pulpotomy: A retrospective human study. ASDC J Dentist Child, 60:107-14.

15: Dean JA, Mack RB, Fulkerson BT, Sanders BJ (2002). Comparison of electrosurgical and formocresol pulpotomy procedures in children. Int J Pediatr Dent, 12:177-82.

16: Bahrololoomi Z, Moeintaghavi A, Emtiazi M, Hosseini G (2008). Clinical and radiographic comparison of primary molars after formocresol and electrosurgical pulpotomy: a randomized clinical trial. Indian J Dent Res,19:219-23.

17: Farrokh Gisoure E (2011). Comparison of three pulpotomy agents in primary molars: a randomised clinical trial. Iran Endod J, 6:11-14.

18: Pescheck A, Pescheck B, Moritz A (2002). Pulpotomy of Primary Molars with the Use of a Carbon Dioxide Laser: Results of a Long-term In Vivo Study. J Oral Laser App, 2;165- 69.

19: Saltzman B, Sigal M, Clokie C, Rukavina J, Titley K, Kulkarni GV (2005). Assessment of a novel alternative to conventional formocresol-zinc oxide eugenol pulpotomy for the treatment of pulpally involved human primary teeth: diode laser-mineral trioxide aggregate pulpotomy. Int J of Paed Dent, 15:437-47.

20: Liu JF (2006). Effects of Nd:YAG laser pulpotomy on human primary molars. J Endod, 32:404-7.

21: Odabas ME, Bodur H, Baris E, Demir C (2007). Clinical, Radiographic, and Histopathologic Evaluation of Nd:YAG Laser Pulpotomy on Human Primary Teeth. J Endod, 33:415-21.

22: Golpayegani MV , Ansari G , Tadayon N, Shams Sh, Mir M (2009). Low-Level Laser Therapy for Pulpotomy Treatment of Primary Molars. J Dent Tehran Univ Med Sci, 6:168-74.

23: Vargas K G, Packham B, Lowman D (2006). Preliminary evaluation of sodium hypochlorite for pulpotomies in primary molars. Pediatr Dent, 28:511-17.

24: Attrill DC, Ashley PF (2001). Occlusal caries detection in primary teeth: a comparison of Diagnodent with conventional methods. Br Dent J, 190:440-3

25: Parkins F, Miller R (1992). Nd:Yag laser analgesia in dentin. J Dent Res, 71:162

26: Visuri SR, Gilbert JL, Wright DD, Wigdor HA, Walsh JT Jr (1996). Shear strength of composite bonded to Er:YAG laser-prepared dentin. J Rest Dent, 75:599-605

27: Yoshida K (2010). Efficacy of Laser treatment for lingual frenectomy. Laser Ther, 19:170-72

28: Ruemping DR, Morton TH Jr, Anderson MW (1983). Electrosurgical pulpotomy in primates- a comparison with formocresol pulpotomy. Pediatr Dent, 5:14-8. 